\title{
Cochlear Implant in a Patient with Arnold-Chiari Syndrome
}

\author{
Maria Stella Arantes do Amaral1,2*, Daniela Soares Fonseca1, Antonio Carlos dos Santos3, \\ Henrique Furlan Pauna1,2, Eduardo T. Massuda1, Ana Cláudia Mirândola Barbosa Reis4, \\ Miguel Angelo Hyppolito ${ }^{1}$
}

${ }^{1}$ Department of Ophthalmology, Otorhinolaryngology, Head and Neck Surgery, Ribeirão Preto Medical School, University of São Paulo, São Paulo, Brazil

${ }^{2}$ Postgraduate Program in Oftalmology, Otorrhinolaryngology and Head and Neck Surgery of the FMRP/USP-Medical Sciences, Department of Ophthalmology, Otorhinolaryngology, Head and Neck Surgery, Ribeirão Preto Medical School, University of São Paulo, São Paulo, Brazil

${ }^{3}$ Department of Clinical Medicine (Center of Image Sciences and Medical Physics), Ribeirão Preto Medical School, University of São Paulo, São Paulo, Brazil

${ }^{4}$ Department of Health Sciences, RCS—Ribeirão Preto Medical School, University of São Paulo, São Paulo, Brazil

Email: *stella_arantes@y ahoo.com, ${ }^{*}$ mariastella_amaral@usp.br

How to cite this paper: do Amaral, M.S.A., Fonseca, D.S., dos Santos, A.C., Pauna, H.F., Massuda, E.T., Reis, A.C.M.B. and Hyppolito, M.A. (2018) Cochlear Implant in a Patient with Arnold-Chiari Syndrome. Case Reports in Clinical Medicine, 7, 162-167.

https://doi.org/10.4236/crcm.2018.72014

Received: January 14, 2018

Accepted: February 24, 2018

Published: February 27, 2018

Copyright $\odot 2018$ by authors and Scientific Research Publishing Inc. This work is licensed under the Creative Commons Attribution International License (CC BY 4.0).

http://creativecommons.org/licenses/by/4.0/

\begin{abstract}
Objective: To verify the efficacy of cochlear implantation in a patient with Arnold-Chiari syndrome. Design: Review of a medical chart from a patient with Arnold-Chiari syndrome that underwent to cochlear implant surgery. Case report: A 6 year-old female, with meningomyelocele and congenital hydrocephalus, deaf in the past 3 years, after meningitis. At that time, she used oral language with adequate speech development. Tone audiometry revealed bilateral profound sensorineural hearing loss. The MRI was compatible with the Arnold-Chiari syndrome. Cochlear implantation was performed on the left ear with MED-EL ${ }^{\otimes}$ Implant (model SONATATi ${ }^{100}$ ). Currently, the child is 12 year-old, performs speech therapy three times a week, with good hearing and language development. Conclusion: Despite the presence of ArnoldChiari syndrome (Chiari type II) with neurological disorders and with ventriculoperitoneal shunt, patient had good hearing results after cochlear implant surgery.
\end{abstract}

\section{Keywords}

Audiometry, Cochlear Implant, Sensorineural Hearing Loss, Arnold-Chiari Syndrome, Deafness, Central Nervous System Malformation

\section{Introduction}

Chiari malformation is a congenital disease of unknown etiology and is charac- 
terized by herniation of posterior fossa contents below the level of the foramen magnum. This malformation is categorized into four types-based on the degree of herniation of these structures-and is presumed to be due to defective closure of the neural tube. According to Chiari's description, type I malformation consists of the caudal displacement of the cerebellar tonsils through the foramen magnum; type II (or Arnold-Chiari malformation) consists in the herniation of the tonsils, IV ventricle and lower portion of the bulb, through the occipital foramen; type III, in herniation of the cerebellum and brainstem within a high cervical meningocele; and type IV, cerebellar hypoplasia without herniation [1]. Yet, it has also been related to traumatic labor [2]. Little is known about these congenital malformations, but genetic mutations were mapped in chromosome $3 q$, but the gene was not precisely located [3].

Arnold-Chiari malformation is usually presented with myelomeningocele, hypoplasia of the posterior fossa, herniation of the encephalon into the cervical spinal canal, and compressive lesions of lower cranial nerves [4].

The clinical picture is determined by the chronic compression of the cervical cord by the cerebellar tonsils. Paralysis of the lower cranial nerves and muscular hypotonia are some of the main characteristics. CT and MRI scans are the preferred radiological studies for the diagnosis of Chiari malformations. Surgical treatment is usually sufficient, with the decompression of the posterior fossa and cervical laminectomy, if the ventricular shunt is patent. If early treatment is instituted, about $88 \%$ of patients have significant remission of symptoms [1] [5]. Here we describe a case of cochlear implantation in a patient with Arnold-Chiari syndrome.

\section{Case Report}

This report was submitted to the ethics committee of our institution and was approved being released from the consent form of the patient or relatives.

A 6 year-old female patient, with congenital meningomyelocele and hydrocephalus attended to the Cochlear Implant Outpatient Clinic of our Hospital, presenting a history of sensorineural hearing loss which started three years before, when she underwent to neurosurgery at other Hospital to replace her ventriculoperitoneal shunt, but developed meningitis after the procedure and the meningitis caused the deafness. At that time, she already presented oral communication. As she was attended first in another hospital there are no records of examinations before the meningitis that caused the deafness.

After evaluation of the multidisciplinary cochlear implant team, patient was fitted with hearing aid, but with no gain in both ears; she presented fair orofacial reading, but could not detect sounds. At that time, she performed two-hour speech therapy, weekly, she showed some regression of the oral language development, and presented delay of her neuropsychomotor development. At the day of her first visit, patient was considered in category zero of hearing, based at Geers Category and category 2 of language, based at Bevilacqua, Delgado and 
Moret Category [6] [7].

Tonal audiometry showed bilateral profound sensorineural hearing loss. MRI examination revealed diffuse white matter reduction, sharp tapering and arching of the corpus callosum, and marked dilation of the ventricles-compatible with Chiari malformation type II (Figure 1). Additionally, patient also presented bilateral lateral semicircular canal hypoplasia and cochlear calcification on the right side. CT scans revealed hypoplasia of bilateral lateral semicircular canals and cochlea to the right (Figure 2).

The child met the criteria for cochlear implant surgery (since the possibility of auditory pathway stimulation was verified), which was performed on the left side with MED-EL ${ }^{\bullet}$ Implant, model SONATATi ${ }^{100}$. On activation, performed 30 days after the surgery, there was no response at " $\mathrm{C}$ level" among the 12 electrodes. However, the patient presented gradual improvement and 6 years after surgery, she performs speech therapy three times a week, and presents category 6 of hearing and category 5 of language development. Figure 3 shows the improvement in hearing and language categories that the patient presented during the period of clinical follow-up.

\section{Discussion}

The Arnold Chiari Syndrome should be suspected in neonatal period when child presents apnea. This apnea can lead to death due to the vocal folds palsy with compression of the brain by myelomeningocele. In older children may appear with gradual weakness of upper extremity. Vandertop et al., in their study, presented $21 \%$ of their cases patients with a myelomeningocele and symptomatic Chiari II malformation [8]. Park et al, found that $18 \%$ of their patients with myelomeningocele developed signs of the Chiari II malformation despite good control of hydrocephalus [9]. The diagnosis is made by nuclear magnetic resonance revealing myelomeningocele. As soon as the diagnosis is made and in

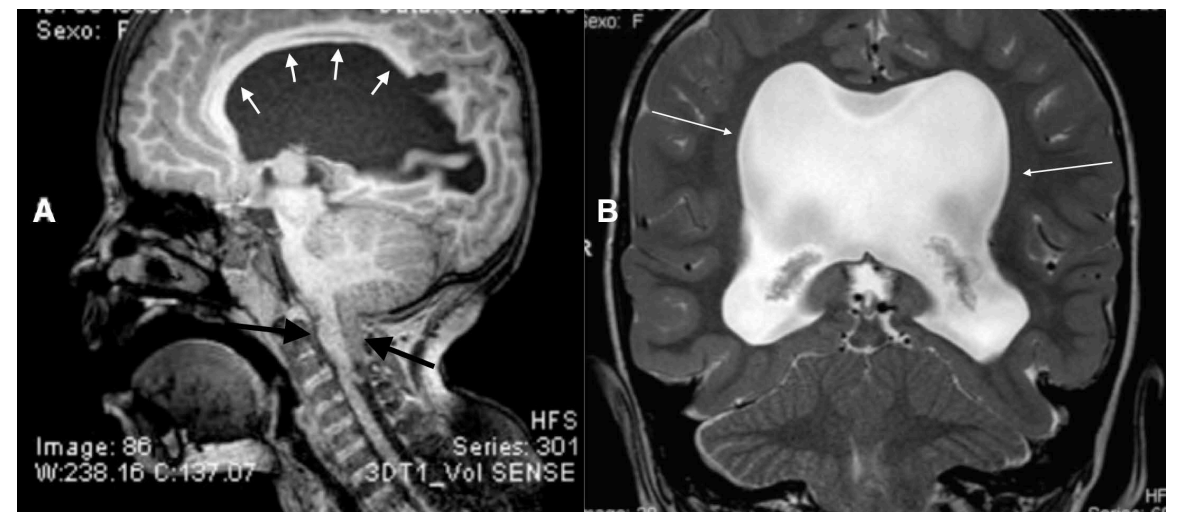

Figure 1. MRI scan obtained from our patient with Arnold-Chiari syndrome. Note diffuse reduction of the white matter, sharp tapering and arching of the corpus callosum (small white arrows), and herniation of tonsils and lower portion of the bulb through the occipital foramen (black arrows, in (A) - sagittal view), and marked dilation of the ventricles (large white arrows in (B) - coronal view). 


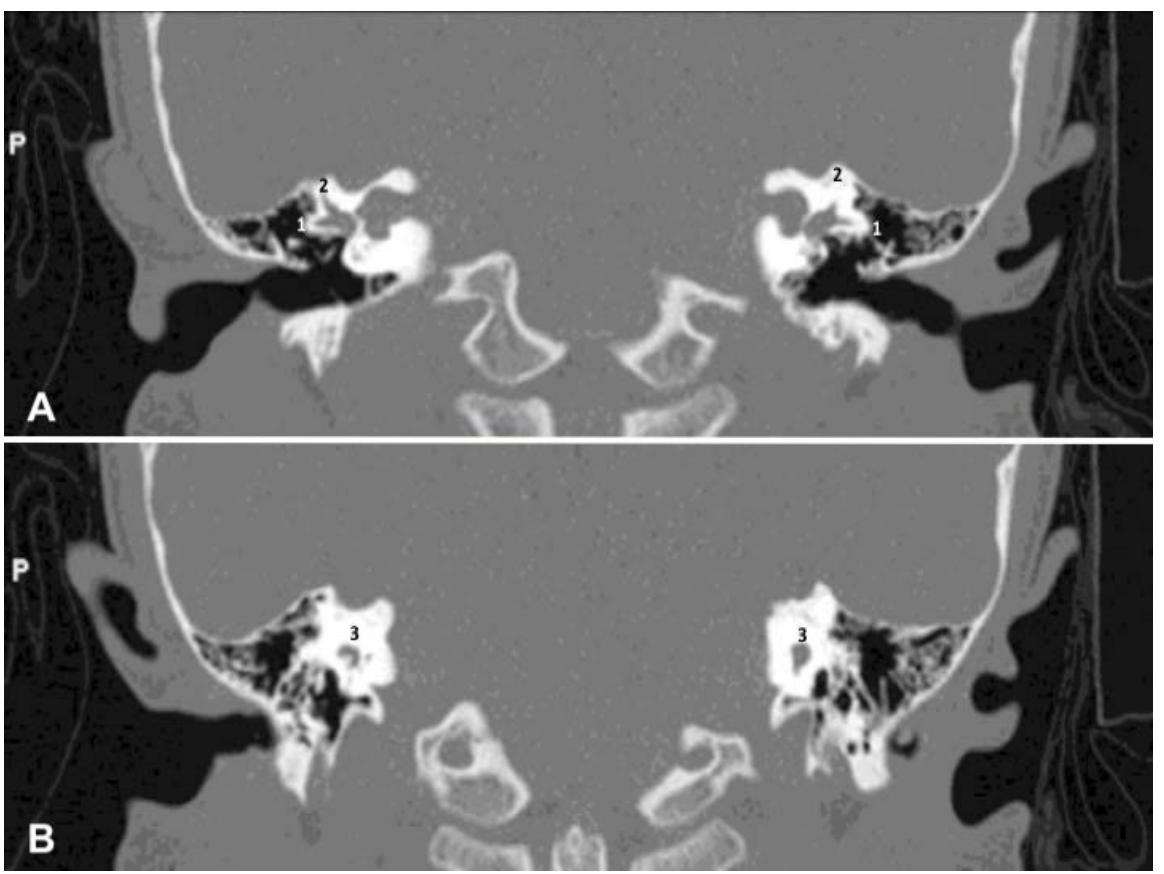

Figure 2. CT scan obtained from our patient with Arnold-Chiari syndrome. Note hypoplasia of bilateral lateral semicircular canals (1 and 2) and cochlea to the right (3).

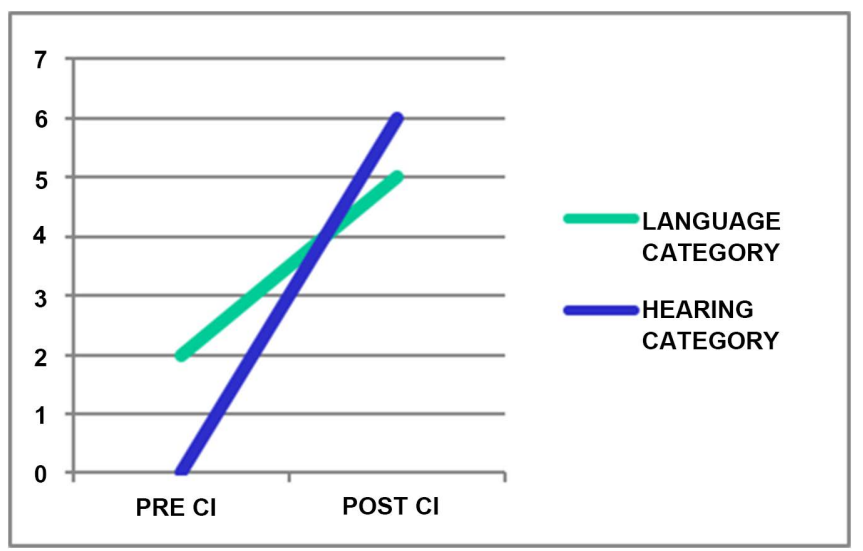

Figure 3. Graphical representation of hearing and language categories, pre- and post-cochlear implantation. POST CI = post-cochlear implantation; PRE CI = pre-cochlear implantation, Numbers 1 to 6 represents numbers of hearing (Geers) and language categories (Bevilacqua, Delgado and Moret).

the case of patient has symptomatology, surgical treatment should be instituted through peritoneal ventricle shunt for treatment of myelomeningocele [8] [9].

As Arnold Chiari Syndrome did not lead to deafness, we didn't find in the literature similar cases of patients with this Syndrome undergoing cochlear implant surgery. Despite the patient's neurological conditions, the same does not interfere with the auditory performance after cochlear implant, especially if the surgical treatment of myelomeningocele is early instituted.

Advances in hearing technology and the improvement of cochlear implant 
surgery techniques, due to improved implant quality, less invasive surgical techniques, and better qualification of cochlear implant team, widen the candidacy for this type of rehabilitation [10].

Neuroimaging has been vital for the correct diagnosis and adequate preoperative evaluation of cochlear implant candidates. In addition, the data obtained may be useful to define the most appropriate timing of follow-up in specific cases and, if necessary, to develop better rehabilitation strategies if the results are different from the expected [11].

Although the patient had Arnold-Chiari syndrome, with hydrocephalus, myelomeningocele and ventriculoperitoneal shunt, a favorable outcome was observed, according to previous studies that reported cases of patients in similar conditions, submitted to cochlear implantation, with good hearing results [12] [13].

\section{Conclusion}

Despite the patient's neurological conditions in Arnold-Chiari syndrome, with hydrocephalus, myelomeningocele and ventriculoperitoneal shunt, a favorable outcome was observed with Cochlear Implantation with improvement of hearing and language categories after Cochlear Implant surgery.

\section{Conflict of Interest}

The authors declare that they have no conflict of interest in this article.

\section{References}

[1] Salomão, J.F., Bellas, A.R., Leibinger, R.D., et al. (1998) Symptomatic Type II Chiari Malformation Arq. Neuro-Psiquiatr, 56, 98-106. https://doi.org/10.1590/S0004-282X1998000100016

[2] Lazareff, J.A. and Valencia-Mayoral, P. (1990) Chiari Malformation. Boletín Médico del Hospital Infantil de México, 47, 719-724.

[3] De Oliveira, A.K.P., Hamerschmidt, R., Mocelin, M., et al. (2012) Cochlear Implantation in Patient with Dandy-Walker Syndrome. International Archives of Otorhinolaryngology, 16, 406-409.

[4] Shuman, R.M. (1995) The Chiari Malformations: A Constellation of Anomalies. Seminars in Pediatric Neurology, 2, 220-226. https://doi.org/10.1016/S1071-9091(05)80033-6

[5] Gammal, T., Mark, E.K. and Brooks, B.S. (1988) MR Imaging of Chiari II Malformation. American Journal of Roentgenology, 150, 163-170. https://doi.org/10.2214/ajr.150.1.163

[6] Geers, A.E. (1994) Techniques for Assessing Auditory Speech Perception and Lipreading Enhancement in Young Deaf Children. The Volta Review, 96, 85-96.

[7] Bevilacqua, M.C., Delgado, E.M.C. and Moret, A.L.M. (1996) Clinical Case Studies of Children at the Educational Center for the Hearing Impaired (CEDAU), the Hospital for Research and Rehabilitation of Lips-Palatal Injuries-USP. In: Costa, O.A. and Bevilacqua, M.C., Eds., XI Encontro Internacional de Audiologia, Bauru, 187. 
[8] Vandertop, W.P., Asai, A., Hoffman, H.J., Drake, J.M., Humphreys, R.P., Rutka, J.T. and Becker, L.E. (1992) Surgical Decompression for Symptomatic Chiari II Malformation in Neonates with Myelomeningocele. Journal of Neurosurgery, 77, 541-544. https://doi.org/10.3171/jns.1992.77.4.0541

[9] Park, T.S., Hoffman, H.J., Hendrick, E.B., et al. (1983) Experience with Surgical Decompression of the Arnold-Chiari Malformation in Young Infants with Myelomeningocele. Neurosurgery, 13, 147-152.

[10] Johnson, P. (2017) Updates in Hearing Technology. North Carolina Medical Journal, 78, 104-106. https://doi.org/10.18043/ncm.78.2.104

[11] Busi, M., Rosignoli, M., Castiglione, A., et al. (2015) Cochlear Implant Outcomes and Genetic Mutations in Children with Ear and Brain Anomalies. BioMed Research International, Article ID: 696281. https://doi.org/10.1155/2015/696281

[12] Chadwick, K.A., Moore, J., Tye, G.W., et al. (2014) Management of Patients with Cochlear Implants and Ventriculoperitoneal Shunts. Cochlear Implants International, 15, 185-190. https://doi.org/10.1179/1754762813Y.0000000055

[13] Wiet, R.M. and El-Kashlan, H.K. (2009) Cochlear Implantation in the Presence of a Programmable Ventriculoperitoneal Shunt. Otology \& Neurotology, 30, 704-707. https://doi.org/10.1097/MAO.0b013e3181b04e3b 